\title{
Vulvar Cancer pN1 TNM Finding v8
}

National Cancer Institute

\section{Source}

National Cancer Institute. Vulvar Cancer pN1 TNM Finding v8. NCI Thesaurus. Code C139610.

Vulvar cancer with regional lymph node metastasis with one or two lymph node metastases each less than $5 \mathrm{~mm}$, or one lymph node metastasis equal to $5 \mathrm{~mm}$. (from AJCC 8th Ed.) 